\title{
INSTRUMENTOS DE PREVENÇAO A DESASTRES: AS MEDIDAS NÃO ESTRUTURAIS E A CONSTRUÇÃO DE CIDADES RESILIENTES
}

Instruments of disaster prevention: non-structural measures and building resilient cities

Instrumentos de prevención de desastres: las medidas no estructurales y la construcción de ciudades resilientes

Délton Winter de Carvalho ${ }^{1}$

1 Pós-Doutor em Direito, University of California at Berkeley, USA. Doutor e Mestre em Direito UNISINOS. Professor do Programa de Pós-Graduação em Direito da UNISINOS. Advogado, Parecerista e Consultor jurídico. deltonwc@via-rs.net. Autor de diversos artigos publicados nacional e internacionalmente, sendo ainda autor dos livros CARVALHO, Délton Winter de. Dano ambiental futuro: a responsabilização civil pelo risco. 2. ed. Porto Alegre: Livraria do Advogado, 2013 e CARVALHO, Délton Winter de; DAMACENA, Fernanda Dalla Libera. Direito dos Desastres. Porto Alegre: Livraria do Advogado, 2013. 
Resumo: O Direito dos Desastres traz à lume uma necessária radicalização da prevenção lato sensu, exigindo um papel protagonista aos instrumentos de avaliação e gestão de riscos catastróficos. Os processos de decisão, seja em sede jurisdicional ou administrativa, devem sempre ser permeados pela necessidade de se evitar e se antecipar aos desastres. Para tanto, uma adequada gestão dos eventos extremos depende de uma consistente consciência acerca dos instrumentos disponíveis para a concretização de uma real governança dos desastres ambientais, processo no qual o Direito deve fornecer estabilidade e dinâmica, mesmo diante de toda a incerteza e indeterminação que permeiam os desastres. Além destes instrumentos deterem força jurídica, limitando a discricionariedade das decisões, estes apresentam importantes informações interdisciplinares, a partir de dados ambientais, científicos, econômicos e infraestruturais, acoplando diversos diálogos transdiciplinarmente.

Abstract: Disaster Law brings to light a necessary radicalization of a broad prevention, requiring a protagonist role of the instruments of catastrophic risk assessment and management. The decision-making processes, whether before a court or administrative agency, must always be permeated by the need to anticipate and avoid disasters. Therefore, proper management of extreme events depends on a consistent awareness of the tools available to achieve real governance of environmental disasters, a process in which the Law should provide stability and dynamics, despite all the uncertainty and indeterminacy that permeate such disasters. Besides these instruments, they also hold legal force, limiting the discretionarity of decision, and presenting important interdisciplinary information from environmental, scientific, economic and infrastructural data, combining various transdisciplinary dialogues.

Resumen: El Derecho de los Desastres saca a luz una necesaria radicalización de la prevención lato sensu, exigiendo un papel protagónico a los instrumentos de evaluación y gestión de riesgos catastróficos. Los procesos de decisión, 
ya sea en sede jurisdiccional o administrativa, deben estar siempre orientados por la necesidad de evitar y anticiparse a los desastres. Para ello, una gestión adecuada de los eventos extremos depende de una consistente consciencia acerca de los instrumentos disponibles para la concreción de una real gobernanza de los desastres ambientales, proceso en el cual el Derecho debe proporcionar estabilidad y dinámica, incluso frente a toda la incertidumbre e indeterminación que permean los desastres. Además de la fuerza jurídica que poseen estos instrumentos, limitando la discrecionalidad de las decisiones, presentan también importantes informaciones interdisciplinarias, a partir de datos ambientales, científicos, económicos e infraestructurales, acoplando transdisciplinariamente diversos diálogos.

\section{INTRODUÇÃO}

$\mathrm{E}$

m casos de regulação jurídica dos desastres, bem como de atuação dos organismos institucionais competentes para lidar com eventos extremos, a prevenção "lato sensu" (prevenção e precaução) exerce um papel central. Isto se dá em razão da própria magnitude extrema dos desastres, assim como suas constantes incertezas e indeterminações causais. A prevenção, de forma circular e sistemática, deve permear e nortear todas as fases de um fenômeno de consequências catastróficas, desde sua prevenção propriamente dita até a reconstrução do patrimônio, da economia e do ambiente afetados.

O Direito, ao seu turno, detém forte vinculação estruturante com o horizonte passado, demonstrando limites e dificuldades operacionais para explorar os instrumentos existentes a fim de demonstrarem os prognósticos razoáveis acerca dos possíveis danos ambientais catastróficos.

A fim de descrever o papel do Direito neste cenário de prevenção dos desastres, o presente texto delimita sua análise sobre a função preventiva do Direito e os diversos instrumentos úteis para a identificação, avaliação, gestão 
e comunicação dos riscos em matéria de desastres. Num primeiro momento, passa-se a explorar os caminhos para subsidiar decisões que tenham a função de identificar e gerenciar os riscos extremos, lançando-se mão de uma descrição e reflexão crítica acerca das medidas estruturais e medidas não estruturais tendentes à prevenção dos riscos catastróficos.

Dentro das medidas estruturais, encontram-se as obras de infraestrutura construídas pelo homem, assim como, mais contemporaneamente, a inserção dos serviços ecossistêmicos como infraestrutura verde ou natural. As pesquisas mais atuais em área de prevenção a desastres demonstram a necessidade de haver a inserção de uma construção de um direito que assegure o meio ambiente ecologicamente equilibrado não apenas como bem jurídico, mas também os serviços ecossistêmicos irradiados por este. Os serviços ecossistêmicos compõem, contemporaneamente, as medidas estruturais, exercendo, também, forte influência sobre as medidas não estruturais, com a sua inserção nos estudos de avaliação de risco e demais medidas não estruturais.

No que diz respeito às medidas não estruturais, o presente trabalho faz sua incursão descritiva e reflexiva sobre os instrumentos tradicionais (abrangência mais ampla em política ambiental) e seu papel na prevenção de desastres. Dentre tais instrumentos, destacam-se o Estudo de Impacto Ambiental e as avaliações de riscos ambientais, dentre outros, adquirindo estes novas nuanças e funções quando utilizados para a prevenção de desastres. Em seguida, trazem-se aqueles, aqui denominados instrumentos de política nacional de proteção e defesa civil, especificamente previstos na legislação específica. Apesar de serem instrumentos, muitas vezes, já existentes no cenário jurídico (como é o caso do Plano Diretor, Cadastros, mapas de riscos, Planos de Emergência, entre outros), estes ganham novas funções e, sobretudo, exercem uma integração de dados e informações, orientando os processos decisórios a partir do Estado de Direito, limitando a discricionariedade, bem como restringindo as possibilidades de decisões alheias à prevenção.

Em face das características do perfil brasileiro de ocorrências de desastres (intensamente ligados a secas, inundações bruscas e processos geológicos e hidrológicos conexos) e das estruturas tradicionais do próprio direito, demonstra- 
se ao final a necessária inserção do horizonte futuro nas decisões acerca da proteção ambiental e da ordenação do solo, a fim de tornar as comunidades e as cidades menos vulneráveis e mais resilientes a catástrofes ambientais.

\section{PREVENÇÃO E MITIGAÇÃO AOS DESASTRES}

Esta fase ganha especial importância em casos de desastres, pois a gestão do risco deve circular e, sistemicamente, permear todas as fases estratégicas de um desastre. A título exemplificativo, mesmo em atividades de reconstrução de infraestruturas de engenharia civil danificadas por um desastre, estas devem ser construídas a fim de evitar novos eventos catastróficos, sendo resilientes a novos eventos, sobretudo no que diz respeito às mudanças climáticas e aos seus eventos climáticos extremos.

Um dos principais desafios à prevenção dos desastres consiste nas características dos próprios riscos catastróficos, sendo estes, em muitos casos, riscos de baixa probabilidade, porém com grandes perdas (vidas, propriedade e serviços ecossistêmicos). A inserção da incerteza nos contextos de decisão dificulta a imposição de medidas preventivas adequadas, pois não há como gerenciar riscos adequadamente se você não consegue medir estes adequadamente. Mesmo o desconhecimento deve ser ponderado, construindo tais descrições sustentadas sobre padrões e programas de decisão principiológicos, tais como a Prevenção (para a qual há a necessidade de descrição quantificável do risco, quer em suas probabilidades e/ou magnitudes) e a Precaução (que gerencia decisões em contextos de dúvida e incerteza científicas a partir de hipóteses cientificamente ponderáveis). A aprendizagem, a informação e os modelos de decisão em contextos de incerteza devem ser tomados em consideração com grande atenção (quer em seu diagnóstico, mas, acima de tudo, em sua fundamentação, atendendo ao Princípio da Motivação das decisões administrativas e jurisdicionais).

O Direito, em sua função preventiva à ocorrência de desastres, deve atuar como um observador da gestão técnica e política do risco, controlando o nível de prevenção em situações críticas. Há, assim, uma estabilidade-dinâmica na operacionalidade do Direito em situações críticas. O Direito ainda serve para trazer à tona, questionar e mapear os pressupostos, pré-juízos e pré-compreensões 
estruturantes da racionalidade social ao longo dos processos de tomada de decisão nas organizações (públicas ou privadas).

A circularidade no gerenciamento dos riscos leva a observação de que sistemas de infraestruturas críticas interconectadas apresentam um padrão para análise e gerenciamento de risco nas fases temporalmente estabelecidas como:i) normalidade que antecede o desastre; ii) interrupção operacional; iii) falha sistêmica; iv) resposta de emergência; v) recuperação dos efeitos do evento; vi) nova normalidade. Nesta equação, deve ser salientado o fato de que, muitas vezes, é possível que a interrupção operacional (que leve a desastres ou colapsos) seja temporária, com o sistema sendo capaz, estruturalmente, de retornar à (velha) normalidade (processo ao qual se denomina restauração). Em casos como estes, muitas vezes não há a percepção de nenhuma interrupção contínua no sistema (seja em relação à infraestrutura de engenharia civil, cibernética ou mesmo verde).

Um sistema em colapso consiste em algo profundamente diverso do sistema em modo operacional normal, apresentando profunda complexidade ao planejamento, ao preparo e, acima de tudo, às respostas emergenciais necessárias, em virtude de sua constante capacidade de apresentar cenários imprevisíveis ou mesmo inimagináveis. Em muitos casos, uma mitigação no período recente pós-desastre faz-se diante de um cenário absolutamente complexo e caótico, sem que tenha havido uma capacidade de antecipação e de preparação adequadas. Esta constatação atribui uma relevância ainda maior às estratégias preventivas a desastres.

Finalmente, o ciclo processual descrito é capaz de demonstrar que, após a recuperação, o que será obtido após o período de recuperação não será uma velha normalidade, mas sim uma nova normalidade, com novas características, tais como estímulos à inovação, novos serviços ecossistêmicos, novas formas cotidianas de vida e novos padrões de qualidade ambiental, gerando novos aprendizados para prevenção de futuras ocorrências. É neste ponto que as irreversibilidades ${ }^{2}$ são percebidas, numa confrontação entre a velha normalidade (pré-desastre) e a nova normalidade (pós-recuperação e restabilização).

2 Acerca do papel da irreversibilidade no Direito, ver: SUNSTEIN, Cass. "Irreversibility." Law, Probability and Risk. v. 9, 3-4, set-dec. London: Oxford University Press, 2010. Tomando em consideração a irreversibilidade na jurisprudência e no Direito brasileiros: CARVALHO, Délton Winter de. "A construção probatória para a declaração jurisdicional da ilicitude dos riscos ambientais." Revista da AJURIS. no 123, ano XXXVIII, set., 2011. 


\section{MEDIDAS ESTRUTURAIS}

No Direito brasileiro, como já referido, a prevenção dos desastres envolve, por evidente, a avaliação (estudo das ameaças, do grau de vulnerabilidade do sistema e dos corpos receptores, e a síntese conclusiva, com a avaliação e hierarquização dos riscos catastróficos e definição das áreas de maior risco) e a gestão dos riscos de desastres (medidas estruturais e não estruturais). As estratégias para atuação preventiva aos desastres são compostas a partir de medidas estruturais e não estruturais.

Nota-se que, tradicionalmente, as medidas estruturais são compreendidas apenas naquelas decorrentes da engenharia civil (infraestrutura construída pelo homem), tais como diques, barragens, obras de contenção de erosão e deslizamentos, entre outras. Por tais motivos, havia, antes da instituição do novo modelo de Política Nacional de Proteção e Defesa Civil (instituído pela Lei n. 12.608/12), a convicção acerca da prioridade das medidas não estruturais sobre as estruturais ${ }^{3}$, dando ênfase às estratégias de construção de informações e conhecimento acerca dos riscos ambientais em detrimento do dispêndio de custos financeiros em obras de infraestrutura civil, geralmente mais onerosas temporal e financeiramente.

Não obstante a relevância das medidas estruturais para a prevenção de desastres, o objeto do presente estudo cinge-se a uma análise das medidas não estruturais, isto é, elementos técnicos consistentes em dados, informações e análises que tenham por objetivo orientar as políticas de gestão de desastres.

\section{MEDIDAS NÃO ESTRUTURAIS:}

Medidas não estruturais em geral

As medidas não estruturais se tratam de estudos, avaliações e autorizações, detendo natureza administrativa e função de produzir informações sociais, econômicas e

3 Cfe. item 1.2. da Política Nacional da Defesa Civil, p. 15: "Em princípio, as medidas nãoestruturais devem ser consideradas prioritariamente." 
ambientais, permitindo processos de tomada de decisão, principalmente pelas instâncias política ejurídica. Tais medidas compreendem estudos, avaliações, licenças, autorizações, entre outros. Portanto, de forma genérica, as medidas não estruturais estão tradicionalmente mais ligadas à ideia de diagnóstico (identificação e avaliação de risco), enquanto que as medidas estruturais dizem respeito mais a estratégias de gestão de risco. Desta forma, nota-se certa impossibilidade de hierarquização e priorização de uma ou outra, devendo haver uma utilização integrada destas estratégias. Da mesma forma, estas estratégias devem ser combinadas e integradas em detrimento de uma utilização fragmentada.

Cada vez mais, impõe-se a articulação entre instrumentos genéricos previstos na Política Nacional de Meio Ambiente (Lei n. 6.938/81) e aqueles previstos especificamente na Política Nacional de Proteção e Defesa Civil (Lei n. 12.608/2012). Assim, as avaliações de impacto ambiental, dentre as quais se destacam o Estudo de Impacto Ambiental - EIA (e respectivo Relatório de Impacto ao Meio Ambiente - RIMA) e as avaliações de riscos ambientais ${ }^{4}$, o zoneamento ambiental ${ }^{5}$, licenciamento ambiental e respectivos estudos que lhe compõem ${ }^{6}$, e a criação de espaços territoriais especialmente protegidos e seus respectivos estudos e laudos ${ }^{7}$ servem de instrumentos não estruturais para a prevenção de riscos ambientais. Com a ampliação e a intensificação dos riscos catastróficos, cada vez mais os piores cenários devem ser compreendidos nos estudos e avaliações que compõem os instrumentos de Política Nacional do Meio Ambiente. Assim, instrumentos de avaliação de riscos ambientais e de vulnerabilidade integrados, de gestão de áreas protegidas, de gestão integrada de ecossistemas e de gestão sustentável de recursos naturais em nível comunitária passam a ter fundamental relevância para a redução de riscos de desastres quando levam em consideração suas probabilidades e magnitudes. Mesmo se tratando de instrumentos de Política Nacional de Meio Ambiente, estes detêm uma relevância destacada como medidas não estruturais preventivas, pois devem integrar aos fatores eminentemente ambientais os riscos socioambientais decorrentes das vulnerabilidades que potencializam os eventos catastróficos.

4 Cfe. art. 9, III, Lei n. 6.938/81.

5 Cfe. art. 9 II, Lei n. 6.938/81.

6 Cfe. art. 9, IV, Lei n. 6.938/81.

7 Cfe. art. 9, VI, Lei n. 6.938/81. 
A título exemplificativo do que se está a dizer aqui, em contextos de áreas de risco de desastres, os Estudos de Impacto Ambiental (EIA) e o seu respectivo Relatório de Impacto ao Meio Ambiente (RIMA) não apenas devem atender aos

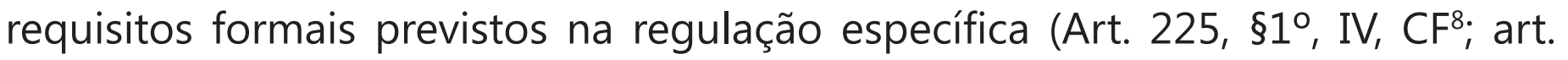
90, III, Lei no 6.938/819; art. $5^{\circ}$ e 6ª , da Resolução do CONAMA) como devem enfrentar, necessariamente, garantir a preocupação com riscos de desastres. Estes estudos detêm a importância de permitir que os impactos sociais, econômicos e ambientais sejam efetivamente tomados em consideração, consistindo em instrumentos verdadeiramente integrados.

Para tanto, faz-se necessária especial atenção às seguintes fases e análises que envolvem os estudos de impacto ambiental e respectivo relatório de impacto ao meio ambiente e sua integração com informações relevantes à prevenção de desastres ambientais ${ }^{10}$ :

(i)Agrupamentodedados:comacoletadedadoslevandoemconsideração riscos naturais e antropogênicos (tecnológicos/industriais) e riscos associados, inclusive aqueles relacionados às mudanças climáticas e variabilidade. Ainda, deve haver coleta simultânea de dados de base do meio ambiente, incluindo identificação dos recursos naturais críticos e dos ecossistemas que apresentam riscos importantes para a regulação dos serviços ecossistêmicos;

(ii) análise das vulnerabilidades ambientais: fazer a identificação dos fatores ambientais componentes dos riscos, como por exemplo, recurso ambientais degradados, funções, geologia, propriedades do solo, hidrologia, regime do clima, que venham por agravar a vulnerabilidade das pessoas, dos seus bens e do meio ambiente a riscos naturais (e que possam apresentar uma ameaça para projetos, programas e planos propostos);

8 "§10. Para assegurar a efetividade desse direito, incumbe ao Poder Público: (omissis) IV exigir, na forma da lei, para instalação de obra ou atividade potencialmente causadora de significativa degradação do meio ambiente, estudo prévio de impacto ambiental, a que se dará publicidade."

9 "art. 90. São instrumentos da Política Nacional do Meio Ambiente: (omissis) III - a avaliação de impactos ambientais."

10 Tais elementos de integração dos Estudos de Impactos Ambientais às estratégias de redução de riscos de desastres são apresentados pelo programa PARTNERSHIP FOR ENVIRONMENT AND DISASTER RISK REDUCTION - PEDRR. Demonstrating the Role of Ecosystem-based Management for Disaster Risk Reduction. Partnership for Environment and Disaster Risk Reduction. ISDR, 2010. p. 19-20. Disponível em: www.pedrr.net. Acesso em: 26.06.2013. 
(iii) análise das consequências potenciais de um projeto, programa ou política em termo de aumento de risco de desastres como resultado de seu impacto sobre o meio ambiente: necessário identificar os possíveis impactos ambientais que aumentam a vulnerabilidade, baseado em diferentes cenários de perigo e risco;

(iv) Identificação e avaliação: identificar e avaliar alternativas com base na aplicação de critérios de sustentabilidade ambiental e cenários diferentes (tais como mudanças climáticas, desastres naturais e riscos induzidos pelo homem). Fazer a identificação e a avaliação das opções de mitigação para reduzir os impactos ambientais potenciais e as vulnerabilidades subjacentes. Realizar a escolha da opção preferida e determinar a sua viabilidade (se recursos financeiros e humanos são suficientes para implementar tais medidas mitigatórias);

(v) tomar em conta a incerteza: dado o elevado nível de incerteza associado com a avaliação de impactos ambientais, o princípio da precaução é aplicado onde os impactos aos ecossistemas não podem ser previstos com confiança, seja em razão do conhecimento limitado em relação aos limiares de resiliência do ecossistema, e/ou onde há incerteza sobre a eficácia da medida mitigatória;

(vi) monitorar: acompanhamento regular bem como avaliação de risco e vulnerabilidade, combinados com critérios de sustentabilidade ambiental após a aprovação de projetos, planos ou programas. Desenvolver indicadores e capacidade institucional para realização de tal monitoramento e avaliação, determinando como eles serão utilizados e monitorados.

Portanto, os instrumentos tradicionais de gestão administrativa dos riscos ${ }^{11}$ pelo Direito Ambiental devem ser permeados pela análise e avaliação da existência de riscos de desastres, com seus fatores e causas humanos, mistos ou naturais, bem como a descrição da vulnerabilidade social, bem como dos serviços ecossistêmicos. Assim, instrumentos de avaliação de risco devem integrar-se de forma constante àqueles de análise e avaliação de vulnerabilidades.

Na atualidade, há não apenas a possibilidade, mas sim a necessidade e o dever de utilização dos instrumentos tradicionais de diagnóstico ambiental, utilizados

11 Acerca da gestão administrativa e jurisdicional dos riscos ambientais, ver: CARVALHO, Délton Winter de. "Sistema constitucional brasileiro para o gerenciamento dos riscos ambientais." Revista de Direito Ambiental. n. 55, São Paulo: Revista dos Tribunais, 2009. 
preponderantemente pelo Direito Ambiental, Administrativo e Urbanístico, para decisões de mitigação e adaptação às mudanças climáticas. Da mesma forma, estes instrumentos devem ser utilizados com o escopo de prevenção e mitigação de desastres, inserindo nestes estudos novos elementos analíticos e sistêmicos, tais como variabilidades climáticas, serviços ecossistêmicos, vulnerabilidades, resiliência, etc. Para tanto, os desastres acabam por exigir uma análise mais ampla dos instrumentos tradicionais de Direito Ambiental, não apenas constando a inserção de elementos ambientais, ecossistêmicos, econômicos e sociais, mas com uma necessária reflexão mais aprofundada.

Há, ainda, instrumentos não estruturais expressamente previstos na Política Nacional de Proteção e Defesa Civil para gestão dos desastres, os quais se passam a analisar.

Medidas Não Estruturais previstas na Lei de Política Nacional de Proteção e Defesa Civil

Apesar de não ser explícita, a Política Nacional de Proteção e Defesa Civil atribui uma preponderância a instrumentos não estruturais em detrimento dos estruturais, em razão do constante custo elevado, maior impactação e maior onerosidade temporal destes últimos. Esta estratégia decorre da compreensão convencional de que as medidas estruturais se limitariam a infraestruturas construídas, olvidando a existência da infraestrutura verde e a possível utilização destas estruturas na redução de riscos de desastres. Uma simples observação lançada sobre a legislação é capaz de demonstrar que esta prevê uma série de instrumentos de natureza não estrutural, fazendo uma pequena menção a medidas estruturais (art. 3-A, parágrafo segundo, III, da Lei 12.340/10, com redação dada pelo art. 22 da Lei n. 12.608), nitidamente vinculando estas (medidas estruturais) apenas à noção de obras de natureza civil.

Como é sabido, os municípios têm a competência exclusiva para legislar sobre códigos de obras e Planos Diretores. Como pode ser observado pela estrutura do Sistema Nacional de Proteção e Defesa Civil (SINPDEC), bem como pela Política Nacional de Proteção e Defesa Civil, os códigos de obras não desempenham 
um papel fundamental na prevenção de desastres no Brasili12, vez não ter havido grandes terremotos ou qualquer incidência de outros eventos sísmicos no país. ${ }^{13}$ Em razão de tratarem-se as inundações e os deslizamentos de terra os eventos mais frequentes e catastróficos, tem havido um percepção no Brasil de que o tratamento destes desastres pode ser mais bem encaminhado por estratégias de ordenamento do solo, tais como Planos Diretores, de natureza de legislação orgânica. Desta forma, os Planos Diretores encontram-se dentro da competência legislativa primária dos municípios ${ }^{14}$, que são obrigados a seguir algumas diretrizes gerais estabelecidas pela União ${ }^{15}$ na Lei Federal ${ }^{16}$.

Exatamente em razão das características dos desastres mais recorrentes no contexto brasileiro (enchentes, deslizamentos e secas), as principais estratégias adotadas na legislação dizem respeito preponderantemente a sistemas de informação para prevenção de desastres e instrumentos de controle e ordenação do solo. Neste sentido, a estrutura nuclear da Política Nacional de Proteção e Defesa Civil está assentada num sistema articulado formado pelo cadastro nacional de municípios com áreas de risco específicos (suscetíveis à ocorrência de deslizamentos de grande impacto, inundações bruscas ou processos geológicos ou hidrológicos correlatos ou cadastro nacional de municípios com áreas de riscos específicos), pelos mapas de risco, Planos Diretores e Planos de Bacia Hidrográfica. Este entrelaçamento de medidas não estruturais, prevalentemente de gestão do solo urbano e de informações, tem por finalidade a formação de deveres de proteção socioambientais. A estrutura nuclear do sistema de medidas não estruturais previstas na Política Nacional de Proteção e Defesa Civil são aqui enfrentadas.

12 Uma despreocupação com os códigos de obra pode, por outro lado, potencializar outros riscos tais como incêndios e desmoronamentos por falhas estruturais em prédios urbanos.

13 INTERNATIONAL RED CROSS. Analysis of Legislation Related to Disaster Risk Reduction in Brazil. Geneva: International Federation of Red Cross and Red Crescent Societies, 2012. p. 27.

14 Em conformidade com o art. 30, VIII da CF.

15 Cfe. art. $21 \mathrm{CF}$.

16 Um bom exemplo neste sentido consiste na Lei n. 10.257/2001, uma das mais relevantes legislações em nível federal em relação a estabelecer um quadro geral para gestão pública urbana. 
Cadastro nacional de municípios com áreas suscetíveis à ocorrência de deslizamentos de grande impacto, inundações bruscas ou processos geológicos ou hidrológicos correlatos

A competência para instituir e manter este cadastro é da União ${ }^{17}$, sendo este um instrumento fundamental para a formação de um sistema articulado de informações e monitoramento das áreas de risco, assim como a adoção de Políticas de Desenvolvimento Urbano pelos municípios. A função primeira do cadastro nacional consiste em efetivar a criação de um verdadeiro sistema nacional de informações e identificação de áreas de risco, a partir do cadastramento das áreas e dos respectivos municípios, que integram áreas especialmente vulneráveis. Tais informações permitem a ação integrada de políticas públicas em nível nacional e regional.

Os municípios incluídos no cadastro nacional de municípios com áreas suscetíveis à ocorrência de deslizamentos de grande impacto, inundações bruscas ou processos geológicos ou hidrológicos correlatos deverão: i) elaborar mapeamento contendo as áreas de risco (de deslizamentos de grande impacto, inundações bruscas ou processos geológicos ou hidrológicos correlatos); ii) elaborar Plano de Contingência de Proteção e Defesa Civil, além de instituir órgãos municipais de defesa civil; iii) elaborar plano de implantação de obras e serviços para a redução de riscos de desastres; iv) criar mecanismos de controle e fiscalização para evitar a edificação em áreas suscetíveis a estas ocorrências; v) elaborar carta geotécnica de aptidão à urbanização (estabelecendo diretrizes urbanísticas voltadas para a segurança dos novos parcelamentos do solo e para o aproveitamento de agregados para a construção civil). ${ }^{18}$

O cadastro institucionaliza os municípios que devem mapear suas áreas, e as informações passam a compor o sistema integrado de informações e monitoramento de desastres. ${ }^{19}$ Esta demanda deve se dar tanto pela história pregressa destes entes federados como pela existência de novas ocorrências. As ocorrências passadas e presentes de desastres vão desencadeando os deveres de

17 Cfe. art. 6, VI, da Lei 12.608/12.

18 Cfe. art. 3-A, parágrafo segundo, Lei n. 12.340/10.

19 Acerca do sistema de informações e monitoramento de desastres ver: art. 6, V, e art. 13, ambos da Lei n. 12.608/12. 
formação de informações (mapas de risco) e a adoção de medidas (alterações de Planos Diretores e restrições habitacionais), simultaneamente com a inclusão dos municípios no referido cadastro. As informações produzidas pelos mapeamentos das áreas de riscos realizadas em nível municipal e estadual (em articulação com a União) devem abastecer e retroalimentar o sistema de informações e monitoramento de desastres, formado, por sua vez, por instrumentos, tais como o cadastro nacional de municípios com áreas suscetíveis à ocorrência de deslizamentos de grande impacto, inundações bruscas ou processos geológicos ou hidrológicos correlatos.

É este sistema que abastece e estimula a execução de um dos objetivos da Política Nacional de Proteção e Defesa Civil, a produção de alertas antecipados sobre a possibilidade de ocorrência de desastres naturais.

Mapas de áreas risco:

Apoiados pela União, tanto os Estados, o Distrito Federal e, especialmente, os Municípios devem identificar e mapear de áreas de risco. ${ }^{20} \mathrm{~A}$ identificação e o mapeamento das áreas de risco devem tomar em conta as cartas geotécnicas, ${ }^{21}$ sendo estas instrumentos a partir dos quais as características e os processos dos meios físicos, bem como do interesse do uso urbano do solo, são apresentados de forma clara e objetiva para compreensão dos usuários finais. É neste instrumento que se faz a confrontação entre as características dos meios físicos em relação às possíveis destinações a serem dadas ao uso e à ocupação do solo, demonstrando a sua compatibilidade ou não, bem como os riscos correlatos. Para tanto, fazse uso de áreas, tais como geologia, geomorfologia, hidrologia, geotecnia, concordando a geociência em geral e a geologia de engenharia.

Ao longo dos últimos anos, tais cartas estão sendo utilizadas para a construção e orientação de Planos Diretores, bem como para a confecção de mapas de risco geomorfológicos, a fim de servirem de instrumentos para a gestão de uso e ocupação do solo urbano, orientando gestores públicos e privados nas decisões de uso do solo.

21 Cfe. Art. 42-A, parágrafo primeiro, da Lei n. 10.257/01. 
Tendo um município, em seu território, uma área suscetível à ocorrência de deslizamentos de grande impacto, inundações bruscas ou processos geológicos ou hidrológicos correlatos, este, bem como seus gestores públicos, estará submetido ao dever de confecção de tais mapas, estando, como já referido, baseada necessariamente nos resultados obtidos na confecção das cartas geotécnicas, sob pena de responsabilização civil do Estado e seus gestores por danos decorrentes de desastres ocorridos nestas áreas em virtude da inação.

Os mapas de risco devem ser diagnósticos socioambientais que, baseados em cartas geotécnicas, devem servisualmente didáticos, em linguagem sistematizada, clara e objetiva. Confeccionados por equipe multidisciplinar, devem levar em consideração não apenas as informações técnicas das vulnerabilidades físicas (provenientes das cartas geotécnicas), mas também as vulnerabilidades sociais. A exemplo do que acontece com o Estudo de Impacto Ambiental (EIA), as cartas geotécnicas e seus respectivos mapas de risco limitam a discricionariedade administrativa dos gestores públicos no exercício de políticas de desenvolvimento urbano. $^{22}$

Sistema de informação e monitoramento de desastres

A instituição de um sistema nacional de informações e de monitoramento de desastres também consiste em competência da União, normativamente assinalada. ${ }^{23}$ A criação de tal sistema ${ }^{24}$ visa ao oferecimento e ao compartilhamento de informações atualizadas para prevenção, mitigação, alerta, resposta e recuperação em situações de desastre no país.

Para tanto, o governo federal criou o Centro de Monitoramento e Alertas de Desastres Naturais (CEMADEN), liderado pelo Ministério da Ciência e Tecnologia. ${ }^{25}$ Localizado na cidade de Cachoeira Paulista (SP), este centro de monitoramento é responsável por gerenciar as informações a partir de dados emitidos pelo radar, 22 Como já decidido no Direito Comparado (direito norte-americano), um Estudo de Impacto Ambiental não dita substancialmente as decisões regulatórias, mas deve, ao menos, forçar um olhar "mais duro" (hard look) e aprofundado para os fatores relevantes envolvendo a matéria e os riscos envolvidos. Ver: Robertson v. Methow Valley Citizens Council, 490 U.S. 332 (1989).

23 Cfe. art. 6, V, da Lei n. 12.608/12.

24 Criação prevista no art. 13, da Lei n. 12.608/12.

25 De acordo com o Decreto Federal n. 7.513/2011. 
pluviômetros e previsões meteorológicas. Entre as atribuições do CEMADEN estão: i) o desenvolvimento de alertas de desastres naturais sobre as ações de proteção e de defesa civil no país, ii) realização e divulgação de estudos e pesquisas visando à produção de informações necessárias para planejar e promover ações preventivas para evitar desastres naturais; iii) operando sistemas informáticos necessários para a preparação de desastres naturais advertências; iv) promoção de atividades de capacitação, treinamento e suporte para a educação em suas áreas de especialização, v) fornecer alertas de desastres naturais para o Centro Nacional de Gerenciamento de Riscos e Desastres (Centro Nacional de Gerenciamento de Riscos e Desastres - $\left(\right.$ enad $\left.^{26}\right)$, que integra o Ministério da Integração Nacional em apoio ao Sistema Nacional de Proteção Civil e Defesa. ${ }^{27}$

A formação do sistema de informações em nível nacional não apenas decorre como se abastece o cadastro nacional e dos mapas (municipais e estaduais) de risco, mas atua, desta forma, combatendo um histórico de problema da "necessidade de ampliação do conhecimento sobre os riscos e desastres, compartilhando bases de dados confiáveis e continuamente alimentadas, com todos os segmentos envolvidos." ${ }^{28}$ A falta de cultura de prevenção no país é potencializada pela existência de bancos de dados e práticas exercidas de maneira fragmentada, tanto no nível no nível estadual quanto municipal. A integração entre o presente sistema, o cadastro e os mapas de risco estabelece a criação de dados acerca das áreas de riscos específicos em nível nacional, unificando, sistematizando e ampliando os dados já existentes.

Planos Diretores:

Os Planos Diretores consistem em instrumentos de zoneamento do solo urbano, obrigatório para municípios constituídos por mais de 20.000,00 (vinte mil)

26 Este centro (Cenad) foi criado pelo Decreto Federal n o 5.376/2005 e sua principal função é melhorar a resposta ao desastre por parte do Estado. Esta organização conta com uma equipe multidisciplinar, com instrumentos para integrar e reunir informações de muitas outras agências governamentais para monitorar situações críticas e gerenciar o processo de preparação e resposta a desastres.

27 De acordo com a informação disponível no Centro de Desastres Naturais Monitoramento e Alerta (Centro de Monitoramento e Alertas de Desastres Naturais - CEMADEN). Disponível em: http://www.cemaden.gov.br. Acessado em: 2013/02/05.

28 MINISTÉRIO DA INTEGRAÇÃO NACIONAL. Plano Nacional de Gestão de Riscos e Resposta a Desastres - PNGRD: Diagnóstico 2012. Rio de Janeiro: FGV, 2012. p. 78. 
habitantes, sendo instrumento básico para qualquer política de desenvolvimento e expansão urbana. ${ }^{29}$

Aqueles municípios incluídos no cadastro nacional de municípios com áreas suscetíveis à ocorrência de deslizamentos de grande impacto, inundações bruscas ou processos geológicos ou hidrológicos correlatos deverão confeccionar seu Plano Diretor, independentemente de seu número de habitantes.

Nos municípios inseridos no referido cadastro nacional, a aprovação de projeto de loteamento e desmembramento de solo (de competência das Prefeituras Municipais ou pelo Distrito Federal, quando for o caso, cfe. art. 12 da Lei 6.766/79) deverá estar vinculada aos requisitos constantes da carta geotécnica de aptidão à urbanização. ${ }^{30}$ Portanto, nestas áreas de risco, definidas como não edificáveis (em Plano Diretor ou em legislação derivada), é vedada a aprovação de projeto de loteamento e desmembramento. ${ }^{31}$ Ainda, é vedada a concessão de licença ou alvará de construção em áreas de risco indicadas como não edificáveis no Plano Diretor ou na legislação derivada. ${ }^{32}$ Em áreas de risco médio, pode haver a existência de restrições parciais, tais como a previsão de condições para a construção regular

29 Art. 182. A política de desenvolvimento urbano, executada pelo Poder Público municipal, conforme diretrizes gerais fixadas em lei, tem por objetivo ordenar o pleno desenvolvimento das funções sociais da cidade e garantir o bem- estar de seus habitantes.

$\S 10$ - O plano diretor, aprovado pela Câmara Municipal, obrigatório para cidades com mais de vinte mil habitantes, é o instrumento básico da política de desenvolvimento e de expansão urbana.

$\S 20$ - A propriedade urbana cumpre sua função social quando atende às exigências fundamentais de ordenação da cidade expressas no plano diretor.

$\S 30$ - As desapropriações de imóveis urbanos serão feitas com prévia e justa indenização em dinheiro.

$\S 40$ - É facultado ao Poder Público municipal, mediante lei específica para área incluída no plano diretor, exigir, nos termos da lei federal, do proprietário do solo urbano não edificado, subutilizado ou não utilizado, que promova seu adequado aproveitamento, sob pena, sucessivamente, de:

I - parcelamento ou edificação compulsórios;

II - imposto sobre a propriedade predial e territorial urbana progressivo no tempo;

III - desapropriação com pagamento mediante títulos da dívida pública de emissão previamente aprovada pelo Senado Federal, com prazo de resgate de até dez anos, em parcelas anuais, iguais e sucessivas, assegurados o valor real da indenização e os juros legais.

30 Cfe. art. 12, parágrafo segundo, da Lei n. 6.766/79.

31 Cfe. art. 12, parágrafo terceiro, Lei n. 6.766/79.

32 Cfe. art. 23 da Lei n. 12.608/12. 
em determinadas áreas do município, sendo estas feitas pela integração das cartas geotécnicas, mapas de risco, Planos Diretores e códigos de construção.

Aqueles municípios que estiverem incluídos no cadastro nacional de municípios com áreas suscetíveis à ocorrência de deslizamentos de grande impacto, inundações bruscas ou processos geológicos ou hidrológicos correlatos deverão, necessariamente, prever em seus Planos Diretores (além dos requisitos genéricos previstos no art. 42 da Lei $10.257 / 01)$ : i) parâmetros de parcelamento, uso e ocupação do solo, de modo a promover a diversidade de usos; ii) mapeamento contendo as áreas suscetíveis à ocorrência de tais riscos; iii) planejamento de ações de intervenção preventiva e realocação de população em áreas de risco de desastre; iv) medidas de drenagem urbana necessárias à prevenção e à mitigação de impactos de desastres; v) diretrizes para regularização fundiária. ${ }^{33}$ A legislação passa também a exigir uma série de condições para os municípios que, inseridos no cadastro nacional de municípios com áreas de risco de desastres, tenham a intensão de ampliar o seu perímetro urbano (após a data de publicação da Lei n. 12.608/12). ${ }^{34}$

33 Cfe. art. 42-A, Lei n. 10.257/01.

34 "Art. 42-B. Os Municípios que pretendam ampliar o seu perímetro urbano após a data de publicação desta Lei deverão elaborar projeto específico que contenha, no mínimo:

I - demarcação do novo perímetro urbano;

II - delimitação dos trechos com restrições à urbanização e dos trechos sujeitos a controle especial em função de ameaça de desastres naturais;

III - definição de diretrizes específicas e de áreas que serão utilizadas para infraestrutura, sistema viário, equipamentos e instalações públicas, urbanas e sociais;

IV - definição de parâmetros de parcelamento, uso e ocupação do solo, de modo a promover a diversidade de usos e contribuir para a geração de emprego e renda;

V - a previsão de áreas para habitação de interesse social por meio da demarcação de zonas especiais de interesse social e de outros instrumentos de política urbana, quando o uso habitacional for permitido;

VI - definição de diretrizes e instrumentos específicos para proteção ambiental e do patrimônio histórico e cultural; e

VII - definição de mecanismos para garantir a justa distribuição dos ônus e benefícios decorrentes do processo de urbanização do território de expansão urbana e a recuperação para a coletividade da valorização imobiliária resultante da ação do poder público.

$\S 1^{\circ}$ O projeto específico de que trata o caput deste artigo deverá ser instituído por lei municipal e atender às diretrizes do plano diretor, quando houver.

$\S 2^{\circ}$ Quando o plano diretor contemplar as exigências estabelecidas no caput, o Município ficará dispensado da elaboração do projeto específico de que trata o caput deste artigo. 
Finalmente, deve-se fazer menção que novas ocupações de áreas de risco devem ser objetos de proibição e fiscalização pelas municipalidades, enquanto que aquelas já existentes devem ser regularizadas mediante a adoção de medidas de redução e controle das vulnerabilidades (infraestrutura verde e cinza; regularizações fundiárias de assentamentos irregulares, como zonas especiais de interesse social, etc.). Tais imposições normativas consistem em verdadeiros deveres de agir, estando o município e seus gestores públicos passíveis de responsabilização civil extracontratual do Estado por omissão.

Verificada a existência de ocupação preexistente destas áreas de risco, o município deverá adotar medidas de redução de riscos de desastres, mediante a execução de plano de contingência e de obras de segurança. Para os casos de ocupações de áreas de riscojá consolidadas e quando estritamente necessário para a segurança dos moradores, a remoção das edificações e o reassentamento dos ocupantes em local seguro estarão condicionados aos seguintes procedimentos: realização de vistoria no local e elaboração de laudo técnico que demonstre os riscos da ocupação para a integridade física dos ocupantes ou de terceiros; e notificação da remoção aos ocupantes acompanhada de cópia do laudo técnico e, quando for o caso, de informações sobre as alternativas oferecidas pelo poder público para assegurar seu direito à moradia. Após tal remoção, a municipalidade deverá adotar medidas para impedir novas ocupações da área. ${ }^{35}$

Planos de Gestão de Bacia Hidrográfica

Para a Política Nacional de Proteção e Defesa Civil, a bacia hidrográfica consistirá na unidade de análise das ações de prevenção de desastres relacionados a corpos dágua ${ }^{36}$, tais como inundações, desmoronamentos provocados por excesso de chuvas, entre outros. Os Planos de Gestão de Bacia Hidrográficas, previstos pela Lei n. 9.433/97, devem estar integrados aos demais instrumentos de Política Nacional de Proteção e Defesa Civil, tais como Planos Diretores, Mapas de Risco, etc.

A título exemplificativo, o Plano Diretor de Bacia Hidrográfica deve, além

$\S 3^{\circ}$ A aprovação de projetos de parcelamento do solo no novo perímetro urbano ficará condicionada à existência do projeto específico e deverá obedecer às suas disposições."

35 Cfe. Disposto no art. 3-B, da Lei n. 12.340/10.

36 Cfe. Art. 4, IV, da Lei n. 12.608/12. 
de realizar o diagnóstico das áreas de risco de inundação ao longo da bacia hidrográfica, indicar, a partir das informações existentes, medidas para restrição de ocupação de áreas de risco e restrições às outorgas de uso de recursos hídricos, sempre com a finalidade de reduzir riscos.

Planos de Proteção e Defesa Civil

Os planos de proteção e defesa civil exercem um papel fundamental no planejamento e no preparo para, caso desastres ocorram, haja a necessária estruturação de diretrizes básicas de atuação durante a resposta emergencial.

Apesar dos desastres serem fenômenos, com frequência, imprevisíveis e de consequências inimagináveis, bem como pelo fato do atendimento a este ter de contar com decisões instantâneas (tomadas em tempo real ao desenrolar do evento e suas consequências), a importância do plano não é apenas estabelecer competências, orientação e guia para as tomadas de decisão no momento oportuno, mas, acima de tudo, obrigar um constate processo institucional e coletivo de reflexão acerca dos desastres, criando um cenário de verdadeiro preparo dinâmico e construtivista.

A elaboração e a instituição dos Planos de Proteção e Defesa Civil são de competência da União ${ }^{37}$ e Estados ${ }^{38}$, enquanto os Planos de Contingência de Proteção e Defesa Civil são atribuídos aos Municípios ${ }^{39}$, para o desenvolvimento de preparo para o atendimento aos desastres.

Em nível federal, o Plano Nacional de Proteção e Defesa Civil deverá conter, pelo menos, a identificação dos riscos de desastres nas regiões geográficas e grandes bacias hidrográficas do país, bem como as diretrizes de ação governamental de proteção e defesa civil no âmbito nacional e regional. Há destaque para a rede de monitoramento meteorológico, hidrológico e geológico e dos riscos biológicos, nucleares e químicos e à produção de alertas antecipados nas regiões de riscos de desastres. ${ }^{40}$ Note-se, neste ponto, que o Plano Nacional não deve estar limitado aos riscos de desastres principalmente enfrentados pela lei, ou seja, aos riscos de deslizamentos de grande impacto, inundações bruscas ou processos geológicos 37 Cfe. art. 6, VIII, Lei n. 12.608/12.

38 Cfe. art. 7, III, Lei n. 12.608/12.

39 Cfe. art. 8, XI, Lei n. 12.608/12.

40 Cfe. art. 6, parágrafo primeiro, Lei n. 12.608/12. 
ou hidrológicos correlatos, devendo apresentar uma visão mais ampla e complexa dos desastres em geral (denominados naturais, artificiais e mistos).

Já em sede estadual, o Plano de Proteção e Defesa Civil demonstra uma redução ao seu objeto obrigatório mínimo, devendo haver a identificação das bacias hidrográficas com risco de ocorrência de desastres e as diretrizes de ação governamental de proteção e defesa civil no âmbito estadual, em especial no que se refere à implantação da rede de monitoramento meteorológico, hidrológico e geológico das bacias com risco de desastre. ${ }^{41}$ Apesar da supressão normativa no caso dos Planos Estaduais, do destaque a rede de monitoramento dos riscos biológicos, nucleares e químicos e à produção de alertas antecipados, constante na previsão normativa para o Plano Federal, é aconselhável a manutenção destes em nível estadual a fim de resguardadas a necessária amplitude dos fatores que podem desencadear desastres e suas múltiplas naturezas. Destarte, apesar da redução, não há, por evidente, limitação ao Estado caso este queira inserir outros objetos e diagnósticos.

Também obrigação dos Municípios incluídos no cadastro nacional, os Planos de Contingência de Proteção e Defesa Civil, devem, em nível local, acompanhar as exigências feitas aos outros entes federados (União e Estado) descritos. Devem, para além daqueles, realizar exercícios simulados regularmente ${ }^{42}$, bem como serem submetidos à avaliação e à prestação de contas anual, por meio de audiência pública, com ampla divulgação. ${ }^{43}$

\section{CONSIDERAÇÕES FINAIS}

A necessária inserção da dimensão futura nos processos de ordenação do solo urbano com vista à gestão dos riscos de desastres

A competência municipal para "promover, no que couber, adequado ordenamento territorial, mediante planejamento e controle do uso, do parcelamento e da ocupação do solo urbano" ${ }^{44}$ lança sobre as municipalidades 41 Cfe. art. 7, parágrafo único, Lei n. 12.608/12.

42 Cfe. art. 8, XI, Lei n. 12.608/12.

43 Cfe. art. 3-A, parágrafo sexto, Lei n. 12.340/10.

44 Cfe. art. 30, VIII, da Constituição Federal Brasileira. 
um papel fundamental na gestão dos riscos de desastres. Tal aspecto é ressaltado pelo fato dos desastres ambientais no Brasil estarem diretamente ligados com a ocupação de áreas de risco, com o descumprimento da legislação ambiental e com o incremento da incidência de eventos climáticos extremos (com destaque para inundações, chuvas extremas e secas).

No caso dos eventos climáticos extremos e sua recente intensificação ${ }^{45}$, devese observar que a ocupação de áreas de risco consiste num fator desencadeador de desastres, tendo as municipalidades um papel central, em gerir e fiscalizar a ordenação do solo, para a prevenção e a mitigação de desastres. O objetivo de planejamento urbano (por planos diretores) é antecipar e guiar. Enquanto antecipar consiste no melhor julgamento tomando em consideração o passado, o ato de guiar se refere a uma série de escolhas positivas para o futuro. Nestes termos, a antecipação consiste num ato empírico, e o guiar, por seu turno, pende para a normatividade. Assim, qualquer engajamento com planejamento é fazer julgamentos enquanto nos antecipamos e guiamos. ${ }^{46}$ Planejamento do solo urbano, desde o início do século $X X$, tem apresentado a tendência de ser bidimensional em cada uma das funções de antecipação e guia, havendo duas variáveis em cada uma destas faces, que são: i) condições mercadológicas (oferta e demanda) e ii) regulação governamental no zoneamento do solo. Para Frank S. Alexander, a experiência de New Orleans, tanto pré quanto pós-Katrina, sugere a necessidade de uma terceira dimensão no planejamento do solo urbano, controlar o solo para o futuro. ${ }^{47}$

Interessante vislumbrar no direito comparado o potencial do planejamento do solo urbano com a inserção da dimensão futura, em casos que favorecem o processo de adaptação às mudanças climáticas. Um bom exemplo disto consiste no caso existente na Califórnia, em que a San Francisco Bay Conservation and Development Commission (Comissão de Conservação e Desenvolvimento da Baia de São Francisco), responsável pela supervisão do desenvolvimento urbano na

45 Tema este objeto de reflexões em CARVALHO, Délton Winter de. "Bases Estruturantes da Política Nacional de Proteção e Defesa Civil a partir de um Direito dos Desastres." Revista de Direito Ambiental. n. 72, São Paulo: Revista dos Tribunais, 2013.

46 ALEXANDER, Frank S.. "Land Use Planning by Design and by Disaster." In: Robin Paul Malloy (ed.). Law and Recovery from Disaster: Hurricane Katrina. Burlington: Ashgate, 2009. p. 65.

47 Idem, ibidem. p. 65-66. 
baía de São Francisco, exige atualmente que novos projetos de construção levem em consideração riscos decorrentes do aumento do nível do mar. Lembre-se de que as mudanças climáticas detêm como um dos principais fatores de riscos futuros exatamente o aumento do nível do mar. No Distrito de Humboldt, a administração pública tem orientado o desenvolvimento costeiro acompanhada da obrigação de aquisição de terras afastadas da costa pelos proprietários, a fim de possibilitar que estes possam realocar suas casas, hoje localizadas à beiramar, assim que o avanço do oceano demande. Nesta localidade, as casas devem ser construídas de forma que seja possível a sua remoção posterior. ${ }^{48}$

\section{REFERÊNCIAS}

ALEXANDER, Frank S. "Land Use Planning by Design and by Disaster." In: Robin Paul Malloy (Ed.). Law and Recovery from Disaster: Hurricane Katrina. Burlington: Ashgate, 2009.

BRASIL. CONSTITUIÇÃO DA REPÚBLICA FEDERATIVA DO BRASIL DE 1988. Disponível em: <http://www.planalto.gov.br/ccivil_03/constituicao/ConstituicaoCompilado.htm>. Acesso em: 03.11.2014.

BRASIL. Decreto Federal $\mathbf{n}{ }^{\circ} \mathbf{5 . 3 7 6} / \mathbf{2 0 0 5}$. Dispõe sobre o Sistema Nacional de Defesa Civil SINDEC e o Conselho Nacional de Defesa Civil, e dá outras providências. Disponível em: <http://www.planalto.gov.br/ccivil_03/_ato2004-2006/2005/Decreto/D5376impressao.htm>. Acesso em: 03.11.2014.

BRASIL. Decreto Federal n. 7.513/2011. Altera o Decreto oㅡ 5.886, de 6 de setembro de 2006, que aprova a Estrutura Regimental e o Quadro Demonstrativo dos Cargos em Comissão e das Funções Gratificadas do Ministério da Ciência e Tecnologia, e dispõe sobre o remanejamento de cargos em comissão. Disponível em: <http://www.planalto.gov.br/ccivil_03/_Ato20112014/2011/Decreto/D7513. htm>. Acesso em: 03.11.2014.

BRASIL. Lei 12.608/12. Institui a Política Nacional de Proteção e Defesa Civil - PNPDEC; dispõe sobre o Sistema Nacional de Proteção e Defesa Civil - SINPDEC e o Conselho Nacional de Proteção e Defesa Civil - CONPDEC; autoriza a criação de sistema de informações e monitoramento de desastres. Disponível em <http://www.planalto.gov.br/ccivil_03/_Ato20112014/2012/Lei/L12608.htm>. Acesso em: 03.11.2014.

48 Informação disponível em: http://www.law.stanford.edu/node/149614. Acesso em 15.04.2013. 
BRASIL. Lei n. 10.257/2001. Regulamenta os arts. 182 e 183 da Constituição Federal, estabelece diretrizes gerais da política urbana e dá outras providências. Disponível em <http://www. planalto.gov.br/ccivil_03/leis/leis_2001/l10257.htm >. Acesso em: 03.11.2014.

BRASIL. Lei n. 12.340/10. Dispõe sobre as transferências de recursos da União aos órgãos e entidades dos Estados, Distrito Federal e Municípios para a execução de ações de prevenção em áreas de risco de desastres e de resposta e de recuperação em áreas atingidas por desastres e sobre o Fundo Nacional para Calamidades Públicas, Proteção e Defesa Civil; e dá outras providências. Disponível em: <http://www.planalto.gov.br/ccivil_03/_ato2007-2010/2010/lei/ I12340.htm>. Acesso em: 03.11.2014.

BRASIL. Lei n. 6.766/79. Dispõe sobre o Parcelamento do Solo Urbano e dá outras Providências. Disponível em: <http://www.planalto.gov.br/ccivil_03/leis/16766.htm>. Acesso em 03.11.2014.

BRASIL. Lei n. 6.938/81. Institui a Política Nacional do Meio Ambiente. Disponível em: < http:// www.planalto.gov.br/ccivil_03/leis/L6938compilada.htm>. Acesso em: 3.11.2014.

BRASIL. Política Nacional da Defesa Civil. <http://www.integracao.gov.br/c/document_ library/get_file?uuid=6aa2e891-98f6-48a6-8f47-147552c57f94\&groupId =10157> acesso em: 03.11.2014.

CARVALHO, Délton Winter de. "A construção probatória para a declaração jurisdicional da ilicitude dos riscos ambientais." Revista da AJURIS. n 123, ano XXXVIII, set., 2011.

CARVALHO, Délton Winter de. "Bases Estruturantes da Política Nacional de Proteção e Defesa Civil a partir de um Direito dos Desastres." Revista de Direito Ambiental. n. 72, São Paulo: Revista dos Tribunais, 2013.

CARVALHO, Délton Winter de. "Sistema constitucional brasileiro para o gerenciamento dos riscos ambientais." Revista de Direito Ambiental. n. 55, São Paulo: Revista dos Tribunais, 2009.

CENTRO de Desastres Naturais Monitoramento e Alerta (Centro de Monitoramento e Alertas de Desastres Naturais - CEMADEN). Disponível em: <http://www.cemaden.gov.br> Acesso em: 2013/02/05.

INTERNATIONAL RED CROSS. Analysis of Legislation Related to Disaster Risk Reduction in Brazil. Geneva: International Federation of Red Cross and Red Crescent Societies, 2012.

PARTNERSHIP FOR ENVIRONMENT AND DISASTER RISK REDUCTION - PEDRR. Demonstrating the Role of Ecosystem-based Management for Disaster Risk Reduction. Partnership for 
Environment and Disaster Risk Reduction. ISDR, 2010. Disponível em: <www.pedrr.net>. Acesso em: 26.06.2013.

ESTADOS UNIDOS DA AMÉRICA. Suprema Corte. CERTIORARI TO THE UNITED STATES COURT OF APPEALS FOR THE NINTH CIRCUIT No. 87-1703. ROBERTSON, CHIEF OF THE FOREST SERVICE, ET AL. V. METHOW VALLEY CITIZENS COUNCIL ET AL. Julgador: John Paul Stevens. 1 maio 1989. Disponível em: <http://caselaw.lp.findlaw.com/scripts/getcase. pl?court=US\&vol=490\&invol=332>. Acesso em: 04.11.2014.

SAN Francisco Bay Conservation and Development Commission. Disponível em: http://www. law.stanford.edu/node/149614. Acesso em: 15.04.2013.

SUNSTEIN, Cass. "Irreversibility." Law, Probability and Risk. v. 9, 3-4, set-dec. London: Oxford University Press, 2010.

Recebido em: nov/2014

Aprovado em: dez/2014 